\title{
Fernanda Sofio
}

\section{Literacura? Psicanálise como forma literária: \\ uma interpretação estética vislumbrada}

(versão corrigida)

\begin{abstract}
Tese apresentada ao Instituto de Psicologia da Universidade de São Paulo como parte das exigências para a obtenção do título de Doutor.
\end{abstract}

Área de concentração: Psicologia Social Orientador: Prof. livre-docente João Augusto Frayze-Pereira

São Paulo 
AUTORIZO A REPRODUÇÃO E DIVULGAÇÃO TOTAL OU PARCIAL DESTE TRABALHO, POR QUALQUER MEIO CONVENCIONAL OU ELETRÔNICO, PARA FINS DE ESTUDO E PESQUISA, DESDE QUE CITADA A FONTE.

Catalogação na publicação Biblioteca Dante Moreira Leite

Instituto de Psicologia da Universidade de São Paulo

Sofio, Fernanda

Literacura? Psicanálise como forma literária: uma interpretação estética vislumbrada / Fernanda Sofio Woolcott; orientador João Augusto Frayze-Pereira. São Paulo, 2013.

$270 \mathrm{f}$.

Tese (Doutorado - Programa de Pós-Graduação em Psicologia. Área de Concentração: Psicologia Social e do Trabalho) - Instituto de Psicologia da Universidade de São Paulo.

1. Psicanálise. 2. Literatura. 3. Estética. 4. Ficção Literária. 5. Caso Clínico. I. Título.

RC504 
Nome: Sofio, Fernanda

Título: Literacura? Psicanálise como forma literária: uma interpretação estética vislumbrada

Tese apresentada ao Instituto de Psicologia da Universidade de São Paulo para obtenção do título de Doutor em Psicologia

Aprovado em 27 de maio de 2013

Banca Examinadora

Prof. João A. Frayze-Pereira

Instituição: Instituto de Psicologia da USP

Assinatura:

Prof. Pedro Meira Monteiro

Instituição: Princeton University

Assinatura:

\section{Prof. Jaime Ginzburg}

Instituição: FFLCH - USP

Assinatura:

Profa. Camila Salles Gonçalves

Instituição: Instituto Sedes Sapientiae

Assinatura:

Prof. Dr. Sylvia Leser de Mello

Instituição: Instituto de Psicologia da USP

Assinatura: 
À outra mãe da neta, minha avó, Piti

Ao pequeno Tadeo, que tanto ensina 


\section{AGRADECIMENTOS}

Ao Prof. João A. Frayze-Pereira, que me estendeu a mão em 2008, oferecendo a indiscutível oportunidade de conduzir esta pesquisa, e entreteceu-a de início a fim com metáforas e ideias, assim como à Dudu, conosco desde o princípio;

À banca de qualificação - os professores Camila Salles Gonçalves e Jaime Ginzburg pelos aportes à época e o generoso aceite de participar da banca avaliadora do trabalho final, ocasião na qual suas contribuições foram ainda mais valiosas - de que destaco a consideração da Profa. Camila Salles Gonçalves, acerca da importância da narrativa clínica psicanalítica para meu trabalho, assim como a perspectiva do Prof. Jaime Ginzburg, de ter se torando de certa forma urgente contemplar a obra de Fabio Herrmann, e particularmente A infância de Adão e outras ficções freudianas, no âmbito da crítica literária brasileira contemporânea;

Aos professores Pedro Meira Monteiro e Sylvia Leser de Mello, que aceitaram compor a banca de doutoramento e cujas arguições foram extremamente cuidadosas e pertinentes entre outras contribuições, o Prof. Pedro Meira Monteiro promoveu o feliz reencontro com os textos de Ricardo Piglia, destacando sua importância para a sustentação teórica da tese principal, e a Profa. Sylvia Leser de Mello indicou aspectos precisos da movediça relação entre Psicanálise e Literatura;

À Profa. Iray Carone, suplente da banca e interlocutora do trabalho em um momento importante de sua feitura, particularmente considerando a ideia de metáfora em Psicanálise;

Aos meus professores, seja na pós-graduação, seja em discussões extramuros universitários, cujos aportes permeiam minha pesquisa e dos quais indicarei as leituras para as quais mais contribuíram - Leandro Karnal (Bíblia e Herrmann), Judith Butler (Kafka), Lewis Miller (Joyce), Joaquim Aguiar (Cândido), Caio Gagliardi (Pessoa), Ana Cecília Olmos (Borges), Munira Mutran (Joyce), Cecília Orsini (Freud e Klein), Maria da Penha Zabani Lanzoni (Freud, Melsohn e Herrmann), Marilsa Taffarel (Melsohn e Herrmann) e Mario Eduardo Costa Pereira (Psicanálise);

Aos primeiros amigos uspianos, Ricardo Gomide (que me incentivou a participar do processo seletivo do doutoramento), Luciana Godoy (que me auxiliou com passos importantes para a elaboração do projeto para a Fapesp) e Gustavo Dionísio (que apoiou minha entrada para o grupo de orientação, que naquela ocasião passava a contar com nós dois);

Aos colegas que chegaram em seguida, na USP e no temporada nos EUA, Renato Tardivo, Deborah Haisch, Abraham Rubin, Alessandra Parente, Vanessa Passarelli, Luiz Moreno, Camila Pavanelli, Graziela Marcheti e Richard Oliveira - suas múltiplas contribuições, indagações e participação ao longo da pesquisa, direta ou indiretamente foram sempre muito importantes;

Às caras colegas de grupo de estudos sobre A infância de Adão e outras ficções freudianas, em 2006, Iliana Warchavchik, Luciana Saddi e Alice Arruda, que estiveram comigo quando 
foram indelevelmente plantadas a curiosidade e a inquietação que floresceram nesta tese;

Aos Magda Khouri, Eliana Caligiuri, Marcio Giovannetti, Claudio Rossi, Guilherme Medina e Myrna Favilli, que me inspiram para continuar perseguindo a Psicanálise, e que em algum sentido foram "coautores" do meu percurso clínico;

Aos vários colegas e amigos que tiveram participações outras no período de elaboração da tese, como Guillermo Parra-Bernal, Flávio Carrança, Ana Maria Rosenzvaig, Ana Cristina Cintra Camargo, Monica Guimarães Teixeira do Amaral, Maria Lucia Castilho Romero, Ana Loffredo, Mara Cristina Souza de Lucia, Leda Barone, Rejane Cutrim, Plínio Montagna, Sonia Carvalho, Sandra Moreira de Souza Freitas, Marina Melsohn Lisbona, Raquel Furgeri, Silvana Rea, Marina Miranda, Pedro Coelho, Rafael Rodrigues, Mariana Bento, Marcia Wada, Carla Regino, Ricardo Portolano, Gabriela Giacomo, Andrea Peruzzolo, Engrácia Perez, Berta Azevedo, Marcia Stroebel, Thelma Bertussi, Carolina Toledo-Piza, Camila Toledo-Piza, Ana Elisa Rocco, Marcos Maldaun, Andressa Freire del Rey, Andrea Adas, Patrícia Banheti, Cris Machado, Adriana Roitman, José Carlos Mohallem, Jessica Morgan;

À Fundação de Amparo à Pesquisa do Estado de São Paulo (FAPESP), assim como à/ao parecerista FAPESP, pelas leituras cuidadosas do trabalho e sugestões importantes no decorrer de sua feitura, e inclusive pela sugestão de pesquisas futuras;

Às instituições que me ofereceram lugares de colaboração e/ou enunciação - USP (IP, FFLCH, HC-FMUSP, IEB e ECA), Columbia, Harvard, CETEC, CCG Psicologia, ISS, SBPSP, APsaA, FEPAL e FEBRAPSI - de onde, pela atenção e eficiência, destaco Nalva e Marcos, do IPUSP, Adele e Fabiana, da SBPSP;

Aos pacientes citados, cujas histórias foram no mínimo duplamente interpretadas, primeiro no momento do trabalho clínico, um exercício conjunto, e depois na escrita da clínica, a interpretação da interpretação;

A Leda e Fabio Herrmann, que já na adolescência comecei a eleger como "pais psicanalíticos", que me acolheram e continuam participando generosamente de meu percurso e formação, cuja participação neste estudo é intrínseca, assim como à Berná, fiel escudeira;

E por fim, últimos e primeiros, à minha família, que me inspira, oferece apoio incondicional e participa de cada conquista, Piti, mamá, papá, Luigi, Chiara, Paquico, Rochi, Nacho, Chiarita, Carla, Karin, Luise, Lucho, Sandra, Alexia, Ludovico, Federico, Giorgio, os avós - não mais conosco - Fernanda, John e Lucho. 


\section{RESUMO}

Sofio, F. (2013) "Literacura"? Psicanálise como forma literária: uma interpretação estética vislumbrada. Tese de doutorado, Instituto de Psicologia, Universidade de São Paulo, São Paulo.

Parte-se da teoria do análogo de Herrmann (2006b) para considerar a possibilidade de identificar Psicanálise (e psicanálises) como forma literária. Segundo esta teoria, todo homem de ciência retira-se para um campo do pensar análogo ao de seu conhecimento. Os físicos retiraram-se para as matemáticas e os cientistas humanos e sociais para a literatura de ficção, assim criando teoria. A meu ver, a teoria do análogo torna possível a afirmação de constituir a literatura de ficção "matéria prima" da Psicanálise; por assim dizer, seus “tijolos”. Entretanto é com Candido (1957/2009) que se torna possível elencar psicanálises mais definitivamente no campo da estética, a partir dos conceitos de função, estrutura e unidade estética. Considerando-se uma possível harmonia entre função e estrutura das psicanálises relatadas, estariam definidas nesse campo. Note-se: se a estrutura de quaisquer psicanálises funciona bem ou mal é menos a questão desta investigação, que pensar se é possível considerá-las nesses termos. Minha pesquisa levanta estas hipóteses a partir de cinco denominadas ficções freudianas de Herrmann (2002a) - que aliás é possível que engendrem um gênero literário, transformado a partir daquele inaugurado nos casos clínicos de Freud - e dois casos clínicos meus. As fiçcoes freudianas de Herrmann e os meus casos clínicos estão estruturados pelo método psicanalítico, descrito por Herrmann (1979), buscado em Freud (1893-1895). Adicionalmente, aquelas consideram a produção da Teoria dos Campos e engendram, definitivamente, unidade estética. Meus casos clínicos - sendo psicanálises - podem ser considerados como forma literária, no sentido desta investigação, mas não é claro que engendrem unidade estética. Esta é uma distinção entre esses dois, digamos "tipos" de psicanálises estudados, entre outros vislumbrados.

Palavras-chave: Psicanálise. Literatura. Estética. Ficção Literária. Caso Clínico. 


\begin{abstract}
Sofio, F. (2013) "Literacure”? Psychoanalysis as literary form: an aesthetic interpretation surmised. Doctoral dissertation, Institute of Psychology, University of Sao Paulo, Sao Paulo.
\end{abstract}

I begin describing the theory of the analogous reign (Herrmann, 2006b), in order to consider Psychoanalysis, and psychoanalyses, as literary form. According to this theory, every man of science removes himself to a field of knowledge analogous to his own, in order to produce knowledge in his particular field. Physicists, for example, remove themselves to the realm of mathematics, and human and social scientists to that of literary fiction, as they produce theory creatively. In my view, it is by the theory of the analogous reign that it has become possible to propose literary fiction as the "raw material" of psychoanalyses: their "building blocks". Nevertheless, it is with Brazilian literary critic Candido (1957/2009) that psychoanalyses may most definitively be contemplated as pertaining to the field of aesthetics, by use of his literary concepts: function, structure and aesthetic unit. In other words, it becomes conceivable that psychoanalyses be aesthetically defined in the realm of Literature, when a harmonious relationship between a psychoanalysis' function and structure is encountered. It must be added that: whether the structure of a particular psychoanalysis functions well or poorly is less the question of this dissertation, than to determine whether it is possible to consider this matter in these terms. My research analyses these hypotheses in four of Herrmann's denominated Freudian fictions (2002a) and two case studies of my own. The former may offer elements to consider the Freudian fiction as a literary genre, as created by Freud and transformed by Herrmann, which is a proposition hinted at by my investigation. In conclusion, I have found that Herrmann's Freudian fictions, like my case studies, are structured by the psychoanalytic method - described by Herrmann (1979) but created by Freud (1893-1895) - although additionally they have the function of considering the theories of the Multiple Fields Theory and they engender aesthetic unity. My case studies may also be considered as literary form - as may psychoanalyses in general, in the sense of this investigation - but it is not clear that they engender aesthetic unity. This is one distinction between these two "types" of psychoanalyses studied, among others surmised.

Keywords: Psychoanalysis. Literature. Aesthetics. Literary Fiction. Case Study. 


\section{SUMÁRIO}

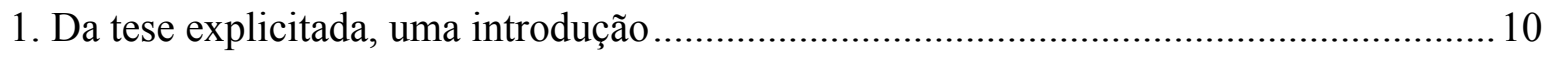

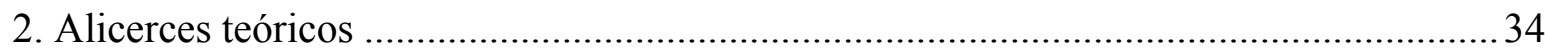

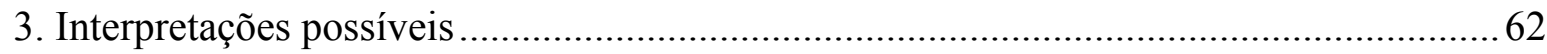

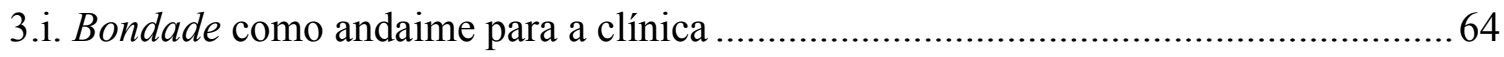

3.ii. Destradução - tempo curto da interpretação psicanalítica .........................................79

3.iii. Tlön justaposta a Límbia e, mais amplamente, Herrmann leitor de Borges...............86

3.iv. "Burocracia kafkiana" n'O escorpião e a tartaruga - um (des)caminho .................. 104

3.v. Ficção joyceana, kafkiana, pessoana (...) - meandros de A infância de Adão ......... 123

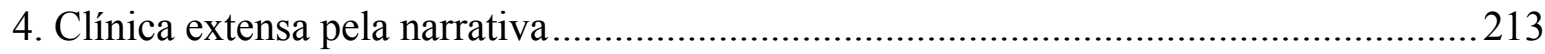

4.i. Encontros, desencontros e reencontros com a histeria, via literacura …..................217

4.ii. Um paciente que são dois (ou mais) - os bilhetes...................................................226

4.iii. Um paciente que são dois - clínica extensa no consultório ....................................234

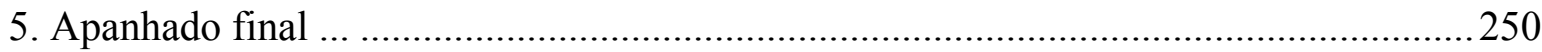

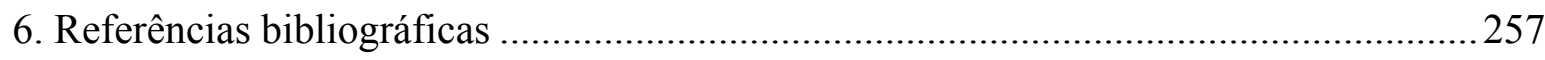




\section{Referências bibliográficas ${ }^{152}$}

Andrade, M. (2007/2008) A dona ausente. Literatura e sociedade: Psicanálise, 10, 272277. (Trabalho original publicado em 1943).

Andrade, O. (2007/2008) Análise de dois tipos de ficção. Literatura e sociedade: Psicanálise, 10, 266-271. (Trabalho original publicado em 1938).

Aristóteles (1961) The poetics. In Fergusson, F. Aristotle's Poetics. (S.H. Butcher, trad.). New York: Hill \& Wang. (Trabalho original de 330 A.C.)

Arrigucci Jr., D. (1996, 03 de abril) Borges ou do conto filosófico. Folha especial, Folha de S. Paulo, 16-19. (Acervo digital)

Arrigucci Jr., D. (1998) Teoria da narrativa: posições do narrador. Jornal de Psicanálise, 31(57), 9-44.

Arrigucci Jr. D. (2007/2008) Entrevista com Davi Arrigucci Jr. Literatura e sociedade: Psicanálise, 10, 312-323. (Trabalho original publicado em 2005).

Azevedo, B.H. (2011) Crise pseudoepiléptica: corpo histeria e dor psíquica. São Paulo: Casa do Psicólogo.

Bachelard, G. (1985) O direito de sonhar. (J.A.M. Pessanha, J. Raas, M.L.D.C. Monteiro e M.I. Raposo, trads.) São Paulo: Difel. (Trabalho original publicado em 1970)

Bachelard, G. (1977) Epistemologia: trechos escolhidos por Dominique Lecourt. (N.C. Caixeiro, trad.). Rio de Janeiro: Zahar.

Bashō, M. (1985) On love and Barley: Haiku of Bashō. (L. Stryk, trad. \& intro.) New York: Penguin classics.

Bastide, R. (1971) Usos e sentidos do termo "estrutura”. (M.H.S. Cappellato, trad.) São Paulo: EDUSP.

Benjamin, W. (2008) Experiência e pobreza. Magia e técnica, arte e política: ensaios sobre literatura e história da cultura. (S.P. Rouanet, trad., Vol. 1, pp. 114-119). São Paulo: Brasiliense. (Trabalho original publicado em 1933)

Benjamin, W. (2007) Franz Kafka: on the tenth anniversary of his death. Illuminations. (H. Zohn, trans., pp. 111-140). New York: Schocken. (Trabalho original publicado em 1934)

\footnotetext{
${ }^{152}$ Segui o modelo de referências APA - American Psychological Association.
} 
Benjamin, W. (2008) O narrador. Considerações sobre a obra de Nikolai Leskov. Magia e técnica, arte e política: ensaios sobre literatura e história da cultura. (S.P. Rouanet., trad., Vol. 1, pp. 197-221). São Paulo: Brasiliense. (Trabalho original publicado em 1936)

Bíblia. (2004) Português. Bíblia de Jerusalém. (E.M. Balancin, trad.) São Paulo: Paulus.

Bíblia. (2009) Português. Bíblia sagrada. (Monges Beneditinos e Maresous (Bélgica), trads.) São Paulo: Ave Maria.

Bion, W. (1967) Notes on memory and desire. The psychoanalytic forum, 2(3). New York: Psychiatric research foundation.

Bleger, J. (1967) Simbiosis y ambigüedad: estudio psicoanalítico. Buenos Aires: Paidós.

Booth, W. (1983) The rhetoric of fiction. Chicago: University of Chicago Press. (Trabalho original publicado em 1961)

Borges, J.L. (1974) La duración del infierno. Discusión. In Jorge Luis Borges, obras completas, 1923-1972. (pp. 235-238) Buenos Aires: Emecé. (Trabalho original publicado em 1929)

Borges, J.L. (1974) Avatares de la tortuga. Discusión. In Jorge Luis Borges, obras completas, 1923-1972. (pp. 254-258) Buenos Aires: Emecé. (Trabalho original publicado em 1932)

Borges, J.L. (versão digital) Tlön, Uqbar, Orbis Tertius. Revista Sur, 68, 30-46. Buenos Aires: Fundación Sur. (Trabalho original publicado em 1940)

Borges, J.L. (2009) Tlön, Uqbar, Orbis Tertius. (Trabalho original publicado em 1940) Ficciones. Madri: Alianza. (Trabalho original publicado em 1944)

Borges, J.L. (1974) La escritura del Dios. El Aleph In Jorge Luis Borges, obras completas, 1923-1972. (pp. 596-599) Buenos Aires: Emecé. (Trabalho original publicado em 1949)

Borges, J.L. (2010) Tlön, Uqbar, Orbis Tertius. Antología de la literatura fantástica. (Borges, J.L., Casares, A.B. e Ocampo, S., orgs.) Buenos Aires: Desbolsillo, pp. 106-21. (Trabalho original publicado em 1965)

Budge, E.A.W. (1967) The papyrus of ani. The Egyptian book of the dead. New York: Dover. (Trabalho original publicado em 1895)

Camargo, A.C.C. (2004a) Entrevista a Fabio Herrmann (dezembro de 2004). Clínica extensa. Dissertação de mestrado. (pp. 40-54) Departamento de Psicanálise, Pontifícia Universidade Católica de São Paulo, São Paulo.

Camargo, A.C.C. (2004b) Clínica extensa. Dissertação de mestrado. Departamento de Psicanálise. Pontifícia Universidade Católica de São Paulo, São Paulo. 
Campos, H.D. (2008) Deus e o diabo no Fausto de Goethe. São Paulo: Perspectiva. (Trabalho original publicado em 1981)

Candido, A.M.S. (2009) Formação da literatura brasileira: momentos decisivos 17501880. São Paulo: Ouro sobre azul. (Trabalho original publicado em 1957)

Candido, A.M.S. (2006) Estrutura literária e função história. Literatura e sociedade. Rio de Janeiro: Ouro sobre Azul. (Originalmente publicada em 1961)

Candido, A.M.S. (2002) A literatura e a formação do homem. Textos de intervenção: seleção. (V. Dantas, apres. e notas) São Paulo: Duas cidades. (Originalmente conferenciado em 1972)

Candido, A.M.S. (2004) O direito à literatura. Vários escritos. São Paulo/Rio de Janeiro: Duas Cidades/Ouro sobre Azul. (pp. 169-191) (Trabalho original de 1988)

Candido, A.M.S. (1997, setembro) Entrevista. Revista investigações. Linguística e teoria literária, 7, 7-39. Pernambuco.

Cariello, G. (1957) Hipertextos para: O escritor argentino e a tradição (fragmentos). (F.S.D. Nardi, trad., pp. 151-162) Discusión. In Jorge Luis Borges, obras completas, 1923-1972. Buenos Aires: Emecé. (Trabalho original publicado em 1929)

Casares, A.B. (2010) Prólogo. (Borges, J.L., Casares, A.B. e Ocampo, S., orgs.) Antología de La literatura fantástica. Buenos Aires: Desbolsillo, pp. 7-14. (Trabalho original publicado em 1940).

Cortázar, J. (2001) Del cuento breve y sus alrededores. Último round: trabajos de estiramiento. Buenos Aires: Siglo veintiuno. (Trabalho original publicado em 1969)

Cortázar, J. (2006) Do conto breve e seus arredores. Valise de cronópio. (D. Arrigucci Jr. e J.A. Barbosa, trads.; H. Campos e D. Arrigucci Jr., orgs.) São Paulo: Perspectiva. (Trabalho original publicado em 1969)

Cunha, A.G.D. (2010) Dicionário etimológico da língua portuguesa. Rio de Janeiro: Lexikon. (Trabalho original publicado em 1982)

Deinert, H. (1964, maio) Kafka's parable "Before the Law". Germanic Review, 39(3), 192200.

Deleuze, G. Foucault. (C.S.A. Martins, trad.) São Paulo: Brasiliense. (Trabalho original publicado em 1986)

Derridá, J. (1992) Before the law. (A. Ronell e C. Roulston, trads., pp. 181-220) Acts of literature. London: Routledge. (Trabalho original apresentado em 1982) 
Ellmann, R. (1982) James Joyce. The first revision of the 1959 classic. Oxford, Inglaterra: Oxford University Press. (Trabalho original publicado em 1959)

Foucault, M. (1994) Que'est-ce qu'un auteur? Dits et Écrits: 1954-1988. Paris : Gallimard, pp. 786-821. (Trabalho original publicado em 1969)

Foucault, M. (2010) What is an author? The Foucault Reader. New York: Vintage books, pp. 73-104. (Trabalho original publicado em 1969)

Foucault, M. (1997) Nietzsche, Freud, Marx. Nietzsche, Freud, Marx. (J. Lima Barreto, trad). São Paulo: Princípio. (Trabalho original publicado em 1975)

Frayze-Pereira, J.A. (2004) Estética, psicanálise implicada e crítica de arte. Revista Brasileira de Psicanálise, 38(2), 443-452.

Frayze-Pereira, J.A. (dezembro, 2007a) Da arte de interpretar o paciente como obra de arte. Jornal de Psicanálise, 40(73), 133-144.

Frayze-Pereira, J.A. (2007b) O impensado de Leda Herrmann. Sobre a morte do autor e o nascimento do leitor. Percurso. Revista de Psicanálise, 38, 31-8.

Frayze-Pereira, J.A. (2010a) Arte, dor: inquietudes entre estética e psicanálise. São Paulo: Ateliê. (Trabalho original publicado em 2006)

Frayze-Pereira, J.A. (2010b) Psicanálise como ciência poética: interpretação e cura. (L. Herrmann et. al, orgs.), Interpretação e cura. V Encontro psicanalítico da Teoria dos Campos Por escrito. (pp. 255-263) São Paulo: Casa do Psicólogo.

Freud, S. (2003) Señorita Elisabeth von R. (Freud). In Estudios sobre la histeria (Breuer y Freud). Sigmund Freud: obras completas. Ordenamiento, comentarios y notas de James Strachey, con la colaboración de Anna Freud. (Vol. II, pp. 151-194) Buenos Aires: Amorrortu. (Trabalho original publicado em 1893-1895)

Freud, S. (2003) Carta 69 (21 de setiembre de 1897). Sigmund Freud: obras completas. Ordenamiento, comentarios y notas de James Strachey, con la colaboración de Anna Freud. (Vol. I, pp. 301-302). Buenos Aires: Amorrortu.

Freud, S. (1987). A interpretação dos sonhos. Edição standard brasileira das Obras psicológicas completas de Sigmund Freud. (Vol. 4 e 5) Rio de Janeiro: Imago. (Trabalho original publicado em 1900).

Freud, S. (2003) Tres ensayos de teoría sexual y otras obras. Sigmund Freud: obras completas. Ordenamiento, comentarios y notas de James Strachey, con la colaboración de Anna Freud. (Vol. VII, pp. 185-218). Buenos Aires: Amorrortu. (Trabalho original publicado em 1905) 
Freud, S. (2003) El delirio y los sueños en la Gradiva de W. Jensen. Sigmund Freud: obras completas. Ordenamiento, comentarios y notas de James Strachey, con la colaboración de Anna Freud. (Vol. IX, pp. 1-88). Buenos Aires: Amorrortu. (Trabalho original publicado em 1907)

Freud, S. (2003) Análisis de la fobia de un niño de cinco años (el pequeño Hans). Sigmund Freud: obras completas. Ordenamiento, comentarios y notas de James Strachey, con la colaboración de Anna Freud. (Vol. X, pp. 1-118). Buenos Aires: Amorrortu. (Trabalho original publicado em 1909).

Freud, S. (2003) Puntualizaciones psicoanalíticas sobre un caso de paranoia (Dementia paranoides) descripto autobiográficamente. Sigmund Freud: obras completas. Ordenamiento, comentarios y notas de James Strachey, con la colaboración de Anna Freud. (Vol. XII, pp. 1-76). Buenos Aires: Amorrortu. (Trabalho original publicado em 1911)

Freud, S. (2003) $4^{\text {a }}$ conferencia: los actos fallidos. (conclusión) Sigmund Freud: obras completas. Ordenamiento, comentarios y notas de James Strachey, con la colaboración de Anna Freud. (Vol. XV, pp. 53-72). Buenos Aires: Amorrortu. (Trabalho original publicado em 1915a)

Freud, S. (2003) Lo inconsciente. Sigmund Freud: obras completas. Ordenamiento, comentarios y notas de James Strachey, con la colaboración de Anna Freud. (Vol. XIV, pp. 153-214). Buenos Aires: Amorrortu. (Trabalho original publicado em 1915b)

Freud, S. (2003) Puntualizaciones sobre el amor de trasferencia (Nuevos consejos sobre la técnica del psicoanálisis, III) Sigmund Freud: obras completas. Ordenamiento, comentarios y notas de James Strachey, con la colaboración de Anna Freud. (Vol. XII, pp. 159-174). Buenos Aires, Amorrortu. (Trabalho original publicado em 1915c)

Freud, S. (2003) Lo ominoso. Sigmund Freud: obras completas. Ordenamiento, comentarios y notas de James Strachey, con la colaboración de Anna Freud. (Vol. XVI, pp. 227-237). Buenos Aires: Amorrortu. (Trabalho original publicado em 1919)

Freud, S. (2003) Más allá del principio de placer. Sigmund Freud: obras completas. Ordenamiento, comentarios y notas de James Strachey, con la colaboración de Anna Freud. (Vol. XVIII, pp. 1-62). Buenos Aires: Amorrortu. (Trabalho original publicado em 1920)

Freud, S. (2003) III. El yo y el superyo (ideal del yo). In El yo y el ello. Sigmund Freud: obras completas. Ordenamiento, comentarios y notas de James Strachey, con la colaboración de Anna Freud. (Vol. XIX, pp. 30-40). Buenos Aires: Amorrortu. (Trabalho original publicado em 1923)

Freud, S. (2003) El sepultamiento del complejo de Edipo. Sigmund Freud: obras completas. Ordenamiento, comentarios y notas de James Strachey, con la colaboración de 
Anna Freud. (Vol. XIX, pp. 177-188). Buenos Aires: Amorrortu. (Trabalho original publicado em 1924a)

Freud, S. (2011) Resumo da Psicanálise. Sigmund Freud Obras Completas. (Vol. 16, p. 227, P.C. Souza, trad.) São Paulo: Companhia das Letras. (Trabalho original publicado em 1924b)

Freud, S. (2003) Fetichismo. Sigmund Freud: obras completas. Ordenamiento, comentarios y notas de James Strachey, con la colaboración de Anna Freud. (Vol. XXI, pp. 141-152). Buenos Aires: Amorrortu. (Trabalho original publicado em 1927)

Gifford, D. e Seidman, R.J. (2008) Ulysses Annotated, Notes for Joyce's Ulysses. London: University of California. (Trabalho original publicado em 1974)

Gombrich, E.H. (2000) Art and illusion: a study in the psychology of pictorial representation. New Jersey: Princeton University Press. (Trabalho original publicado em 1960)

Gullar, F. (2000) Traduzir-se. Na vertigem do dia. Rio de Janeiro: Civilização. In Toda poesia. Rio de Janeiro: José Olympio. (Trabalho original publicado em 1980)

Hegel, G.W.F. (2010) O sistema das artes: curso de estética. (A. Ribeiro, trad.) São Paulo: Martins Fontes. (Trabalho original publicado em 1820-1829)

Herrmann, F. (texto não publicado a) Anotando a china (viagem psicanalítica ao oriente).

Herrmann, F. (texto não publicado b) Da clínica extensa à alta teoria: meditações clínicas. $188 \mathrm{pp}$.

Herrmann, F. (texto não publicado c) Quem faz o que é feito? In Terceira meditação: o tempo, o sujeito e a cura. Da clínica extensa à alta teoria: meditações clínicas.

Herrmann, F. (texto não publicado d) Segunda meditação: O análogo. Da clínica extensa à alta teoria: meditações clínicas.

Herrmann, F. (1979) Andaimes do real: uma revisão crítica do método da Psicanálise. (Coleção Sedes Sapientiae) São Paulo: E.P.U. (Editora Pedagógica e Universitária Ltda.)

Herrmann, F. (1983a, 12 de junho) Horkos ou "Pelos charutos de Freud". Folhetim, Folha de S. Paulo, 8-9. (Acervo digital)

Herrmann, F. (1983b) O Homem Psicanalítico: identidade e crença. Revista brasileira de Psicanálise, XVII(4), 417-427.

Herrmann, F. (1986a) Convergências e divergências entre as várias teorias e práticas psicanalíticas. Revista Brasileira de Psicanálise, 20(4), 553-565. 
Herrmann, F. (1986b) Sobre o ofício da função terapêutica. In Simpósio de las Américas. Gualajara, México.

Herrmann, F. (1989) Introdução e interpretação: a invariância do método nas várias teorias a práticas clínicas. Interpretação: sobre o método da psicanálise. (S.A. Figueira, org., pp. 7-34) Rio de Janeiro: Imago. (Trabalho original apresentado em 1988)

Herrmann, F. (1991a) Andaimes do real: o método da Psicanálise. São Paulo: Brasiliense. (Trabalho original publicado em 1979)

Herrmann, F. (1991b) Clínica psicanalítica: a arte da interpretação. São Paulo: Brasiliense.

Herrmann, F. (1994) Mal-estar na cultura e a Psicanálise no fim de século. (Junqueira Filho, L.C.U., coord.) Perturbador mundo novo: história, psicanálise e sociedade contemporânea. São Paulo: Escuta.

Herrmann, F. (1999a) A psique e o eu. São Paulo: HePsiquê.

Herrmann, F. (1999b) O momento da Teoria dos Campos na Psicanálise. O psicanalista hoje e amanhã: o II encontro da Teoria dos Campos por escrito. (L.M.C. Barone et. al, orgs., pp. 11-24) São Paulo: Casa do Psicólogo.

Herrmann, F. (2000a) A cura. Jornal de Psicanálise, 33(60/61), 425-444.

Herrmann, F. (2000b) Entrevista: Fabio Herrmann. Jornal de Psicanálise, 33(60/61), 6388.

Herrmann, F. (2001a) Andaimes do real: psicanálise do quotidiano. São Paulo: Casa do Psicólogo. (Trabalho original publicado em 1985)

Herrmann, F. (2001b) Introdução à Teoria dos Campos. São Paulo: Casa do Psicólogo.

Herrmann, F. (2001c) O momento da Psicanálise. Andaimes do real: psicanálise do quotidiano. (pp. 12-32) São Paulo: Casa do Psicólogo. (Trabalho original publicado em 1985)

Herrmann, F. (2002a) A infância de Adão e outras ficções freudianas. São Paulo: Casa do Psicólogo.

Herrmann, F. (2002b) Da clínica extensa à alta teoria: a história da Psicanálise como resistência à Psicanálise. Percurso Revista de Psicanálise, 15(29), 15-20.

Herrmann, F. (2002c) Daqui p'ra frente. O psicanalista: hoje e amanhã. O II Encontro Psicanalítico da Teoria dos Campos por escrito. (L.M.C. Barone et. al., orgs., pp. 281-291) São Paulo: Casa do Psicólogo. 
Herrmann, F. (2003a) A travessia da incerteza (sobre a clínica extensa no consultório). Jornal de Psicanálise, 36(66/67), 167-196.

Herrmann, F. (2003b) Resenha de $A$ viagem - da literatura à psicanálise, de Noemi Moritz Kon. Ide, 38, 99-101.

Herrmann, F. (2004) Pesquisando com o método psicanalítico. Pesquisando com o método psicanalítico. (F. Herrmann e T. Lowenkraun, orgs., pp. 43-83) São Paulo: Casa do Psicólogo.

Herrmann, F. (2005) Clínica extensa. A Psicanálise e a clínica extensa: III encontro da Teoria dos Campos por escrito. (L. Barone et. al., orgs., pp. 17-31) São Paulo: Casa do Psicólogo.

Herrmann, F. (2006a) Andaimes do real: psicanálise da crença. São Paulo: Casa do Psicólogo. (Trabalho original publicado em 1998)

Herrmann, F. (2006b) O análogo. Revista Educação. Especial: biblioteca do professor: Freud, 1., 74-83.

Herrmann, F. (2007, junho) Sobre a infância de Adão. Percurso. Revista de Psicanálise, 38, ano XIX, 11-22.

Herrmann, F. (2008a) Freud e o pensamento por ruptura de campo. Ruptura de campo: crítica e clínica. IV Encontro psicanalítico da Teoria dos Campos por escrito. (L. Herrmann et al., orgs., pp. 13-16). São Paulo: Casa do Psicólogo.

Herrmann, F. (2008b) Pensamento por ruptura de campo. Ruptura de campo: crítica e clínica. IV Encontro psicanalítico da Teoria dos Campos por escrito. (L. Herrmann et al., orgs., pp. 27-32). São Paulo: Casa do Psicólogo.

Herrmann, F. (2008c) A interpretação e suas teias. Ruptura de campo: crítica e clínica. IV Encontro psicanalítico da Teoria dos Campos por escrito. (L. Herrmann et al., orgs., pp. 209-216). São Paulo: Casa do Psicólogo.

Herrmann, F. (2008d) A arte da interpretação. Ruptura de campo: crítica e clínica. IV Encontro psicanalítico da Teoria dos Campos por escrito. (L. Herrmann et al., orgs., pp. 255-259). São Paulo: Casa do Psicólogo.

Herrmann, F. (2007/2008e) A ficção freudiana. Nota introdutória. Literatura e sociedade: Psicanálise, 10, 278-285. (Trabalho original publicado em 2002)

Herrmann, F. (2012a) Sobre a verdade como tensão entre invenção e descoberta (I// $\underline{V} / / \mathrm{D})$. Revista Brasileira de Psicanálise, 46(3), 65-77.

Herrmann, F. e Herrmann, L. (2012b) Quem? Hoje, Joyce. Revista Ide, 34(53), 109-122. 
Herrmann, L. (2005) Introdução à Teoria dos Campos: conceitos metodológicos. $A$ Psicanálise e a clínica extensa. III encontro psicanalítico da Teoria dos Campos por escrito. (L. Barone, et. al., orgs, pp. 33-39). São Paulo: Casa do Psicólogo.

Herrmann, L. (2006) A episteme da Psicanálise: uma contribuição da Teoria dos Campos. Jornal de Psicanálise, 39, 81-96.

Herrmann, L. (2007) Andaimes do real: a construção de um pensamento. São Paulo: Casa do Psicólogo. (Trabalho original publicado em 2004)

Herrmann, L. (2010) Teoria dos Campos: uma psicanálise brasileira. Reflexões Psicanalíticas 2009. (pp. 181-197). São Paulo: Artes Médicas.

Herrmann, L. (2012, 17-18 de agosto) O par analítico: uma conversa estranha. Encontro Ítalo-Brasileiro de Psicanálise. Congresso Internacional sobre Corpo em Psicanálise, VII, Aracaju, SE.

Hinshelwood, R., Robinson, S. e Zarate, O. (2011) Melanie Klein: a graphic guide. London: Icon. (Trabalho original publicado em 1997)

James, W. (2007) The principles of psychology. (Vol. 1.) New York: Cosimo classics. (Trabalho original publicado em 1889)

Japiassú, H. (1976) Para ler Bachelard. Rio de Janeiro: F. Alves.

Jones, E. (1989) A vida e a obra de Sigmund Freud. (Vol. 2., J.C. Guimarães, trad.) Rio de Janeiro: Imago. (Trabalho original publicado em 1953)

Joyce, J. (2000) Dubliners. New York: Penguin Modern Classics. (Trabalho original publicado em 1914)

Joyce, J. (2003) A portrait of the artist as a young man. New York: Penguin Classics. (Trabalho original publicado em 1916)

Joyce, J. (1990) Ulysses. New York: The Gabler Edition (Vintage). (Trabalho original publicado em 1934)

Joyce, J. (2012) Finnegans Wake. Oxford: Oxford World's Classics. (Trabalho original publicado em 1939)

Kafka, F. (1971a) Description of a struggle. The complete stories. (pp. 9-51) New York: Schocken. (Trabalho original publicado em 1908)

Kafka, F. (1971b) The judgment. The complete stories. (pp. 77-88) Nova York: Schocken. (Trabalho original publicado em 1912)

Kafka, F. (1971c) The complete stories. New York: Schocken. 
Kafka, F. (2008) Letter to my father. (H. Coyler, trans.) North Carolina, USA: Lulu. (Trabalho original de 1919)

Kafka, F. (2009) The trial. Oxford, Inglaterra: OUP Oxford. (Trabalho original publicado em 1925)

Kafka, F. (1961) Parables and paradoxes: in German and English. (C. Greenberg, E. Kaiser et al., trans.) New York: Schocken. (Trabalho original publicado em 1935)

Kafka, F. (1976) Diaries, 1910-1923. (J. Kresh, M. Greenberg e H. Arendt, trans.) New York, Schocken. (Trabalho original publicado em 1948)

Kafka, F. (1983, 3 de julho) Diante da lei, conto de Franz Kafka. (M. Carone, trad.) Folhetim, Folha de S. Paulo, 12. (Acervo digital)

Klein, M. (versão digital) Notes on some schizoid mechanisms. The international journal of Psychoanalysis, 27, 99-109. (Trabalho original publicado em 1946)

Klein, M. (1975) The psycho-analysis of children. The writings of Melanie Klein. (A. Strachey, trad.). London: Hogarth. (trabalho original publicado em 1932).

Kon, N.M. (2003a) A viagem: da literatura à Psicanálise. São Paulo: Companhia das Letras. (Trabalho original publicado em 2001)

Kon, N.M. (2003b) Fiç̧ões freudianas, ficções herrmannianas. Ide, 37, 95-99.

Kuhn, T.S. (1996) The structure of scientific revolutions. ( $3^{\mathrm{a}}$ ed.) Chicago: University of Chicago Press. (Trabalho original publicado em 1962)

Laplanche, J. e Pontalis, J.B. (2001) Vocabulário da Psicanálise. (P. Tamen, trad.) São Paulo: Martins Fontes. (Trabalho original publicado em 1982)

Leite, D.M. (1979) O amor romântico e outros temas. São Paulo: Nacional/EDUSP.

Leminski, P. (1983) Matsuó Bashō. Coleção Encanto Radical. São Paulo: Brasiliense.

Lenin, V.I. (1981) Esquerdismo, doença infantil do comunismo. São Paulo: Global. (Trabalho original publicado em 1920)

Lévi-Strauss, C. (1968) Estruturalismo: antologia de textos teóricos. (E.P. Coelho, seleção e intro.; M.E.R. Colares, A.R. Rosa e E.P. Coelho, trads.). Lisboa: Portugália. (Trabalho original publicado em 1963)

Lucia, M.C.S.D., Herrmann, F. et. al. (manuscrito) Avaliação e intervenção psicanalítica de pacientes com diagnóstico prévio de pseudoepilepsia a partir da Teoria dos Campos: proposta preliminar. 
Mannoni, M. (1982) A teoria como ficção: Freud, Groddeck, Winnicott, Lacan. (Trad. R.C. Lacerda \& W. Dutra). Rio de Janeiro: Campus. (Trabalho original publicado em 1979)

Marx, K. (2010) O capital: critica da economia política. Rio de Janeiro: Civilização Brasileira. (Trabalho original publicado em 1857)

Marx, K. e Engels, F. (2007) Manifesto of the Communist Party. (S. Moore, trad.) Virginia, VA: Wilder. (Trabalho original publicado em 1848)

Maupassant, G.D. (1909) Le horla: - le voyage du horla - un fou? Paris: Louis Conard. (Trabalho original publicado em 1887)

Melsohn, I. (1991) Notas críticas sobre o inconsciente, sentido e significação: a função expressiva e a constituição do sentido. Ide, 21, 18-47.

Meneses, A.B.D. (2005) A literatura e a organização da experiência. A Psicanálise e a clínica extensa. III encontro psicanalítico da Teoria dos Campos por escrito. (L. Barone et al. orgs., pp. 121-136) São Paulo: Casa do Psicólogo.

Meneses, A.B.D. (2010a) Grande Sertão: Veredas e a "Psicanálise" de Riobaldo. Cores de Rosa: ensaios sobre Guimarães Rosa. (pp. 21-54) São Paulo: Ateliê.

Meneses, A.B.D. (2010b) O Quem dos Lugares: A passionalização da natureza em Grande Sertão: Veredas. Cores de Rosa: ensaios sobre Guimarães Rosa. (pp. 55-74) São Paulo: Ateliê.

Molloy, S. (1999) Las letras de Borges. Rosario, Argentina: Beatriz Viterbo.

Mora, J.F. (2001) Dicionário de filosofia. (R.L. Ferreira e A. Cabral, trads.) São Paulo: Martins Fontes. (Trabalho original publicado em 1994)

Nunes, B. (1966) A vida nos bastidores. Suplemento literário, O Estado de S. Paulo, 5. (Acervo digital)

Nunes, B. (2002) Literatura e filosofia: (Grande sertão: veredas). Teoria da literatura em suas fontes (L. Costa Lima, org., Vol. 1, pp 199-220). Rio de Janeiro: Civilização Brasileira.

Olmos, A.C. (2005) Por que ler Borges. São Paulo: Globo.

Passos, C.R. (1995) Confluências - crítica literária e psicanálise. São Paulo: EDUSP.

Pereira, S.M.C.P. et. al. (2005) Pseudoepilepsia: avaliação e intervenção psicanalíticas através da Teoria dos Campos. In Congresso Interamericano de Psicologia da Saúde: Território e Percursos do Psicólogo Hospitalar, III, São Paulo. 
Perrone-Moisés, L. (2007/2008) A fala esvaziada em Nelson Rodrigues. Literatura e sociedade: Psicanálise, 10, 58-69.

Pessoa, F. (1996) A voz de Deus. Poesias ocultistas. (J.A. Neves, p. 50) São Paulo: Aquariana.

Pessoa, F. (1984) Duas cartas a Adolfo Casais Monteiro sobre a gênese dos heterônimos. In Tabucchi, A. Pessoana mínima: escritos sobre Fernando Pessoa. Lisboa: Imprensa nacional - Casa da Moeda. (Carta original de 1935)

Petot, J.M. (2003) A inveja. Melanie Klein II: o ego e o bom objeto: 1932-60. (P.B. Haber et. al., trads., pp. 155-162) São Paulo: Perspectiva. (Trabalho original publicado em 1982)

Piglia, R. (2004) Formas breves. (J.M.M. Macedo, trad.) São Paulo: Companhia das Letras. (Trabalho original publicado em 2000)

Piglia, R. (2006) O último leitor. (H. Jahn, trad.) São Paulo: Companhia das Letras.

Pontalis, J.B. (1994) A estação da Psicanálise. (M. Marques, trad.) Jornal de Psicanálise, 27(52), 95-112.

Pontalis, J.B. (1998) Processo ou travessia? (M. Marques, trad.) Jornal de Psicanálise, $31(57), 265-275$.

Rimbaud, A. (1967) Une saison en enfer. Rimbaud: complete work, selected letters. (pp. 173-211) Chicago: Chicago University Press. (Trabalho original publicado em 1873)

Rosa, J.G. (2001) Grande sertão: Veredas. Rio de Janeiro: Nova Fronteira. (Trabalho original publicado em 1967)

Rosenbaum, Y. (2012, dezembro) Literatura e psicanálise: reflexões. FronteiraZ: revista digital do programa de estudos pós-graduados em literatura e crítica literária da PUC-SP, 9, 225-234.

Rosenfeld, A. (1966, 12 de março) Kafka, hoje. Suplemento literário, O Estado de S. Paulo, 2. (Acervo digital)

Rosenfeld, A. (2011) Literatura e personagem. A personagem de ficção. (pp. 9-50) São Paulo: Perspectiva.

Sampaio, C.P. (2000) Ficção literária: terceira margem na clínica psicanalítica. Tese de Doutorado, Departamento de Psicologia Clínica, Pontifícia Universidade Católica de São Paulo, São Paulo.

Sampaio, C.P. (2005) Conjugações entre Psicanálise e literatura. A Psicanálise e a clínica extensa: III Encontro Psicanalítico da Teoria dos Campos por escrito. (L. Barone et. al. orgs., pp. 163-182) São Paulo: Casa do Psicólogo. 
Sarlo, B. (2007) Borges, un escritor en las orillas. Buenos Aires: Seix Barral. (Trabalho original publicado em 1993)

Schwarz, R. (1966, 12 de março) A tribulação do pai de família: tradução e comentário de Roberto Schwarz. Suplemento literário, O Estado de S. Paulo, 4. (Acervo digital)

Shakespeare, W. (1957) The tragedy of Hamlet, Prince of Denmark. Baltimore: Penguin Books. (Trabalho original publicado entre 1599 e 1601)

Sister, B.M. e Taffarel, M. (1996) Isaías Melsohn: a psicanálise e a vida: setenta anos de histórias paulistanas e a formação de um pensamento renovador na psicanálise. São Paulo: Escuta.

Sofio, F. e Mohallem, J.C. (2006) Pseudo-epilepsia y la histeria. In Congresso da Federação Psicanalítica da América Latina, XXVI, Lima, Peru.

Sofio, F. (2007) Função terapêutica e hospital: onde há Psicanálise? Dissertação de mestrado, Departamento de Psicologia Clínica, Pontifícia Universidade Católica de São Paulo, São Paulo.

Sofio, F. (2008) A riqueza da Teoria dos Campos no trabalho clínico e acadêmico: rigor teórico e flexibilidade literária. Fabio Herrmann - uma viagem psicanalítica. (pp. 225-234) São Paulo: Pedro e João Editores.

Sofio, F. (2009, dezembro) O conceito de erro necessário levado às últimas circunstâncias: "O escorpião e a tartaruga". Percurso. Revista de Psicanálise, 42(ano XXI), 101-106.

Sofio, F. (2010) Literacura? Psicanálise como forma literária. Revista Brasileira de Psicanálise, 44(4), 149-55.

Sofio, F. (2011) Um paciente que são dois - clínica extensa no consultório. Revista Trieb, $X(1-2), 129-146$.

Sofio, F. (2012a) A Psicanálise na UTI. In Congresso da Federação Psicanalítica da América Latina, XXIX, São Paulo.

Sofio, F. (2012b) Description or storytelling as production of reality. Kafka's Description of a struggle. (manuscrito)

Sousa, C.H.M.R., Brito, E.M e Santos, M.C.R. (2005) A recepção da obra de Franz Kafka no Brasil. Pandeaemonium germanicum, 9, 227-253.

Stella, F. e Pereira, M.E.C. (mar. 2003) Semiologia e características clínicas das crises pseudoepilépticas. Revista latinoamericana de psicopatologia fundamental, VI(1), 109-129. 
Taffarel, M. (2005) O método psicanalítico - sua identificação desde a história da Psicanálise e sua relação com o método nas ciências. Tese de Doutorado, Departamento de Psicologia Clínica, Pontifícia Universidade Católica de São Paulo, São Paulo.

Ueda, M. (1990) Matsuo Bashō: the master haiku poet. New York: Kodansha International. (Trabalho original publicado em 1970)

Viala, A. (January, 2004) Review: Le littéraire, qu'est-ce que c'est? French studies: a quarterly review, 58(1): 149-150.

Waltke, B.K. (2005) The valiant wife (31: 10-31). The book of proverbs: chapters 15-31. The new international commentary on the Old Testament. (pp. 510-532) Cambridge, Reino Unido: Eerdmans.

Weiner, J. S. (1980) The Piltdown forgery. New York: Dover. (Trabalho original publicado em 1965) 